\title{
The Effect of Furosemide on the Level of Neutrophil Gelatinase-associated Lipocalin in Critically Hospitalized Patients with Acute Kidney Injury
}

\author{
Hadi Hamishehkar, Sarvin Sanaie', Vahid Fattahi², Mehran Mesgari ${ }^{3}$, Ata Mahmoodpoor ${ }^{2}$ \\ Department of Clinical Pharmacy, Applied Drug Research Center, Tabriz University of Medical Sciences, ${ }^{1}$ Tuberculosis and Lung Disease Research Center, Tabriz \\ University of Medical Sciences, ${ }^{2}$ Department of Anesthesiology and Intensive Care Medicine, Faculty of Medicine, Tabriz University of Medical Sciences, ${ }^{3}$ Drug Applied \\ Therapeutic Research Center, Radio Immunoassay Lab, Tabriz University of Medical Sciences, Tabriz, Iran
}

\section{Abstract}

Background and Aims: Oliguric acute kidney injury (AKI), commonly attributed to a more severe degree of renal injury, is associated with poorer prognosis than nonoliguric form. The aim of this study was to determine the effect of furosemide therapy on kidney function and on the level of neutrophil gelatinase-associated lipocalin (NGAL) in critically hospitalized patients in the Intensive Care Unit (ICU). Materials and Methods: In this randomized controlled trial, 106 ICU patients with AKI were assigned into furosemide and control groups. In furosemide group, $40-80 \mathrm{mg}$ of intravenous furosemide was administrated, followed by $1-5 \mathrm{mg} / \mathrm{h}$ furosemide infusion. In control group, patients received standard treatment. Serum and urinary NGAL were measured on the $1^{\text {st }}, 3^{\text {rd }}$, and $7^{\text {th }}$ days of the study. Results: The results of this study indicated that during the study, serum blood urea nitrogen levels of patients increased in both groups; this, however, was significant only in the control group $(P=0.009)$. Both plasma and urine NGAL decreased significantly $(P<0.05)$ in both groups. The findings of 28 -day mortality follow-up revealed that $20 \%$ and $28 \%$ of patients died in the furosemide and the control groups, respectively. Conclusions: NGAL was not found to reflect any positive or negative effects of Furosemide in patients with AKI.

Keywords: Acute kidney injury, furosemide, Intensive Care Unit, plasma neutrophil gelatinase-associated lipocalin, urine neutrophil gelatinase-associated lipocalin

\section{INTRODUCTION}

Acute kidney injury (AKI) is defined as a sudden and continuous decrease in glomerular filtration rate (GFR) which results in accumulation of urea and other toxins in blood. AKI is classified based on AKI Network or risk, injury, failure, loss, end-stage (RIFLE) classification into three groups (1/at risk, 2/injury, 3/failure). ${ }^{[1]}$ Oliguric AKI is correlated with kidney injury and is accompanied by further degrees of injury compared to nonoliguric AKI. ${ }^{[2]}$ Aiming at volume status control, physicians try to use diuretics to convert oliguric AKI to nonoliguric AKI which is associated with lower mortality rate. Response to diuretic therapy during $\mathrm{AKI}$ is equal to less severity of disease and some studies showed that diuretic usage could not only reduce the mortality but also might result in higher mortality rates. ${ }^{[2,3]}$ Relation between volume status and kidney injury is complicated as in critically ill

\begin{tabular}{|l|l|}
\hline \multicolumn{3}{c|}{ Access this article online } \\
\hline Quick Response Code: & Website: \\
& www.ijccm.org \\
\hline
\end{tabular}

patients, volume overload means that these patients depend on more volume to keep their hemodynamics stable. On the other hand, volume overload is a marker of organ damage and increased mortality. ${ }^{[4]}$ Furosemide is used routinely in AKI, ${ }^{[5]}$ but some studies showed that it is ineffective in reducing the rate of acute tubular necrosis. ${ }^{[6]}$ In contrast, some other studies have suggested that furosemide is not only ineffective in fixed $\mathrm{AKI},{ }^{[7]}$ but also could increase mortality. ${ }^{[8]}$ On the other hand, loop diuretics could reduce metabolic demands and oxygen consumption of kidney tubular cells and protect kidney throughout ischemia. ${ }^{[9]}$ Diuretics also increase renal blood

Address for correspondence: Prof. Ata Mahmoodpoor, General ICU, Shohada Hospital, Golgasht Street, Tabriz, Iran. E-mail:amahmoodpoor@yahoo.com

This is an open access article distributed under the terms of the Creative Commons Attribution-NonCommercial-ShareAlike 3.0 License, which allows others to remix, tweak, and build upon the work non-commercially, as long as the author is credited and the new creations are licensed under the identical terms.

For reprints contact: reprints@medknow.com

How to cite this article: Hamishehkar H, Sanaie S, Fattahi V, Mesgari M, Mahmoodpoor A. The effect of furosemide on the level of neutrophil gelatinase-associated lipocalin in critically hospitalized patients with acute kidney injury. Indian J Crit Care Med 2017;21:442-7. 
flow through inhibition of prostaglandine dehydrogenase. ${ }^{[10]}$ In a meta-analysis, it was shown that furosemide is ineffective in prevention of AKI, but could reduce volume overload and reduce mechanical ventilation period in hemodynamically stable patients. ${ }^{[10]}$ Furosemide facilitates excretion of electrolytes and toxins and results in improved acid-base status and electrolyte imbalance. ${ }^{[11,12]}$ Recently, new biomarkers have been developed for early detection of AKI the two most important of which are neutrophil gelatinase-associated lipocalin (NGAL) and cystatin C. Based on newer studies, cystatin $\mathrm{C}$ is of no significant importance in $\mathrm{AKI} .{ }^{[13]} \mathrm{NGAL}$ is secreted from nephron and its level increases $48 \mathrm{~h}$ before increase in serum or urine creatinine $(\mathrm{Cr})$ levels $^{[14]}$ turning them to useful biomarkers for early detection of AKI, especially in postcardiac surgeries, radiocontrast exposure, and Pediatric Intensive Care Unit (ICU) patients. ${ }^{[15,16]}$ However, serum NGAL is a highly sensitive yet nonspecific marker for AKI in septic patients, ${ }^{[17]}$ so there are many challenges in diagnosis and treatment of AKI patients. The aim of this study was to evaluate the effect of adding furosemide in oliguric AKI patients on the levels of biomarkers presented kidney function to find any benefits in attempt to convert oliguric AKI patients to nonoliguric ones.

\section{Materials and Methods}

After obtaining ethics approval, 106 patients were enrolled in this randomized clinical trial. Informed written consent was obtained from patients or their surrogates from August 2012 to October 2014 in ICU of two university-affiliated hospitals. We are planning a study of a continuous response variable (plasma NGAL [pNGAL]) from independent control and experimental (furosemide) individuals with 1 control(s) per experimental individual. In a pilot study, the response within each individual group was normally distributed with standard deviation (SD) 53.98. The true difference in the experimental and control means was $30 \mathrm{mg} / \mathrm{l}$ so we will need to study 48 experimental individuals and 48 controls to be able to reject the null hypothesis that the population means of the experimental and control groups are equal with probability (power) 0.8 . The Type I error probability associated with this test of this null hypothesis is 0.05 . Individuals were randomized into two groups using Internet-based software (Trial registration number: IRCT201205092582N8). During the study, two patients were died, three were ineligible after enrolment and one declined to participate, so the final analysis was performed on 100 patients.

\section{Definition of acute kidney injury}

AKI was defined using urine output and $\mathrm{Cr}$ criteria of the RIFLE classification. ${ }^{[18]}$ Patients were included in the study if their $\mathrm{Cr}$ rose to more than $150 \%-300 \%$ or urine output decreased to $<0.5 \mathrm{cc} / \mathrm{kg} / \mathrm{h}$ for $12 \mathrm{~h}$ or more. Exclusion criteria were previous history of AKI, renal replacement therapy, renal transplantation, urinary system obstruction, previous history of diuretic use, alkalosis, or hypovolemia.

\section{Study procedure}

We used furosemide in oliguric critically ill patients. In the intervention group $(F)$, patients received furosemide $40-80 \mathrm{mg}$ IV bolus (based on mean blood pressure and volume status of patients) and then received furosemide with an infusion dose of $1-5 \mathrm{mg} / \mathrm{h}$. This dose was titrated based on urine output of more than $0.5 \mathrm{ml} / \mathrm{kg} / \mathrm{h}$. In the control group (C), patients did not receive any diuretic. We injected furosemide based on patients mean arterial pressure (MAP) and volume status. We tried to keep the central venous pressure (CVP) more than $10 \mathrm{mmHg}$, and we optimized the patients volume of status to reach the target CVP before furosemide injection. In MAP $>65 \mathrm{mmHg}$ or $\mathrm{CVP}<15$, we used $40 \mathrm{mg}$ furosemide but if MAP was more than $65 \mathrm{mmHg}$ and CVP was more than 15 we injected $80 \mathrm{mg}$ furosemide. Infusion was started with $1 \mathrm{mg} / \mathrm{h}$ in all patients and adjusted based on response till $5 \mathrm{mg} / \mathrm{h}$. Drugs with kidney clearance were adjusted and nephrotoxic drugs discontinued in all patients if possible. We used norepinephrine as vasopressor in our patients if they require vasopressor. Demographic data and electrolytes were noted for all patients. Urinary and serum NGAL were assayed for all patients on $1^{\text {st }}, 3^{\text {rd }}$, and $7^{\text {th }}$ day of the study. Plasma $\mathrm{Cr}$ was assayed with enzymatic photometric method. Urinary enzymes were assayed with Vitros 250 analyzer. GFR was calculated using Cockcroft-Gault formula. NGAL was assessed by enzyme-linked immunosorbent assay with a commercial kit (BioVendor, Prague, Czech). Blood and urinary samples were taken on $1^{\text {st }}, 3^{\text {rd }}$, and $7^{\text {th }}$ day from patients. Samples were centrifuged for $10 \mathrm{~min}$ at $3000 \mathrm{r} / \mathrm{min}$ and frozen in $-80^{\circ} \mathrm{C}$ until data analysis. Serum and urine samples were diluted 30 and 10 times with buffer dilution just before the assay, respectively. The aim of our study was to evaluate kidney biomarkers (blood urea nitrogen [BUN], Cr, pNGAL, urine NGAL [uNGAL]) in AKI patients. During the study, patients were followed and if they developed the following signs or symptoms renal replacement therapy was started: Volume overload resistant to medical therapy, severe acidosis resistant to medical treatment, severe electrolyte imbalance resistant to treatment, uremic signs or symptoms, and progressive azotemia in the absence of uremia.

\section{Statistical analysis}

Continuous and categorical data were compared between two groups with Student's $t$-test and Chi-square test, respectively. Repeated measurement analysis of variance was used to compare differences in evaluated biomarkers between and within two groups during sequential measured times. Greenhouse-Geisser test was used when Mauchly's test of sphericity was significant to test the significant changes of biomarkers within each group. All data were presented as mean $\pm \mathrm{SD} . P<0.05$ was considered statistically significant.

\section{RESULTS}

Table 1 presents clinical characteristics of patients. Most patients had neurologic manifestations. Higher levels of Acute Physiology and Chronic Health Evaluation and Sequential 


\begin{tabular}{|c|c|c|c|}
\hline & $\begin{array}{l}\text { AKI treated } \\
\text { with } \\
\text { furosemide } \\
(n=50)\end{array}$ & $\begin{array}{l}\text { AKI treated } \\
\text { without } \\
\text { furosemide } \\
(n=50)\end{array}$ & $P$ \\
\hline Age & $64.8 \pm 11.3$ & $61.2 \pm 11.2$ & 0.12 \\
\hline Male & $34(68)$ & $30(60)$ & 0.41 \\
\hline Admission diagnosis & & & 0.89 \\
\hline Neurologic & $17(34)$ & $20(40)$ & \\
\hline Cardiovascular & $4(8)$ & $2(4)$ & \\
\hline Trauma & $7(14)$ & $8(16)$ & \\
\hline Pulmonary emboli & $10(20)$ & $10(20)$ & \\
\hline Sepsis & $12(24)$ & $10(20)$ & \\
\hline APACHE II & $23.8 \pm 5.8$ & $24.6 \pm 4.8$ & 0.45 \\
\hline SOFA & $11.68 \pm 2.89$ & $12.08 \pm 2.43$ & 0.59 \\
\hline $\mathrm{CVP}\left(\mathrm{cmH}_{2} \mathrm{O}\right)$ & $13.8 \pm 3.8$ & $14.5 \pm 3.9$ & 0.35 \\
\hline Use of vasopressors & $18(36)$ & $26(52)$ & 0.10 \\
\hline ICU mortality & $10(20)$ & $14(28)$ & 0.35 \\
\hline Mechanical ventilation & $32(64)$ & $28(56)$ & 0.25 \\
\hline RIFLE category at enrolment & & & 0.63 \\
\hline Risk & $26(52)$ & $24(48)$ & \\
\hline Injury & $14(28)$ & $16(32)$ & \\
\hline Failure & $10(20)$ & $10(20)$ & \\
\hline
\end{tabular}

Data are presented as mean \pm SD or $n(\%)$. APACHE: Acute Physiology and Chronic Health Evaluation; SOFA: Sequential Organ Failure Assessment; CVP: Central venous pressure; ICU: Intensive Care Unit; RIFLE: Risk, injury, failure, loss, end-stage; SD: Standard deviation; AKI: Acute kidney injury

Organ Failure Assessment scores indicate that patients with critically ill conditions were enrolled in this study. Number of patients with CVP more than $15 \mathrm{mmHg}$ in Group C were 15 versus 17 patients in Group F. More than $50 \%$ of patients were mechanically ventilated. There were not significant differences in stages of RIFLE criteria between two groups. Nearly, $50 \%$ of patients were in at-risk stage of RIFL criteria. Mean urine volume in Group F was $2450 \pm 235 \mathrm{ml}$ vs $427 \pm 36 \mathrm{ml}$ in Group C $(P<0.05)$. Fluid balance between two groups did not have any significant different. Group $\mathrm{F}$ was associated with lower level of $\mathrm{Cr}$ and pNGAL but higher level of BUN at enrolment compared to the Group C [Table 2]. Significant differences were observed in trends of $\mathrm{Cr}$ and pNGAL between two groups during 7 days $(P<0.05)$ [Figures 1 and 2]. The values of $\mathrm{Cr}$ and pNGAL were higher in Group C comparing with Group F in only $1^{\text {st }}$ day and $1^{\text {st }}$ and $3^{\text {rd }}$ days, respectively [Table 2]. No significant differences were found in UNGAL (urine), BUN trends of changes during measured times between two groups $(P>0.05)$ [Figures 1 and 2]. pNGAL and UNGAL values decreased during time in both groups $(P<0.05)$. Changes in trends of BUN during measured times were incremental in both groups $(P<0.05)$. The $\mathrm{Cr}$ values were not changed significantly during time within Groups $\mathrm{F}$ and $\mathrm{C}(P=0.053$ and $P=0.077$, respectively). No significant difference was found in CRRT requirement between two groups $(P>0.05)$. Twenty-eight days mortality was $20 \%$ and $28 \%$ in Groups F and C, respectively; the difference was not significant between two groups.

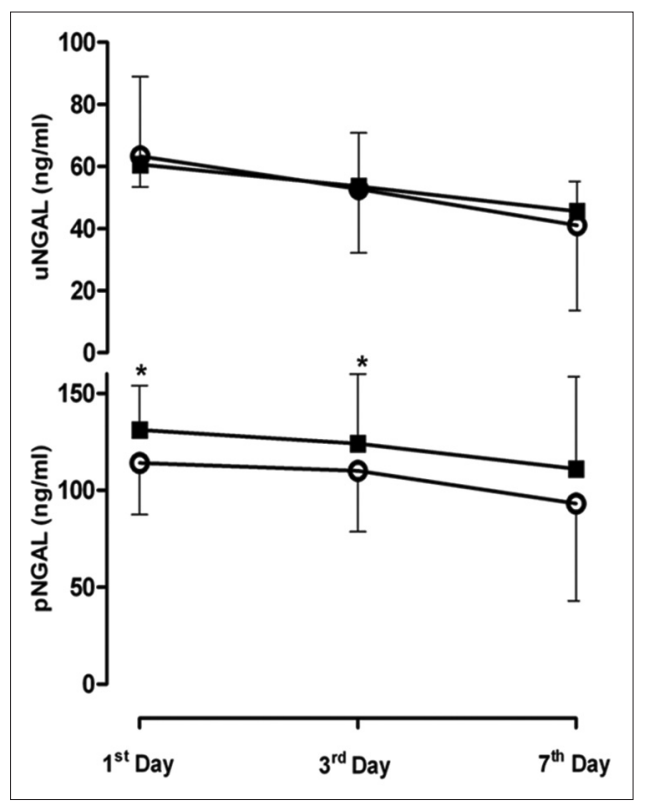

Figure 1: Changes in plasma concentration of UNGAL and pNGAL for Furosemide vs. control group by day. Open circles, Furosemide group; Solid Square, control group. This figure shows that trend of change in UNGAL during 7 days is not significantly different in both group $(P>0.05)$. Trend of pNGAL is significantly lower in Furosemide group comparing with control. ${ }^{\star} P<0.05$ for difference between pNGAL in Furosemide versus control group in first and third days after development of AKI

\section{Discussion}

Our study results revealed that furosemide does not have any positive effect on AKI phase biomarkers in critically ill patients admitted to ICU. Because of higher level of pNGAL and $\mathrm{Cr}$ in Group $\mathrm{C}$ and decreasing pattern of them in both groups, it seems that lower trends of pNGAL and $\mathrm{Cr}$ in Group F comparing with Group C do not show the efficacy of furosemide. Decrease in urinary volume is the first indicator of AKI. Recent evidence suggests that instead of a single mechanism being responsible for AKI cause, critical illness is associated with an entire orchestra of involving factors such as cellular mechanisms, adaptive and maladaptive, which potentiate each other and ultimately give rise to clinical AKI. Hence, based on this complex pathophysiology, many patients with different pathologies could develop AKI. Our study population was almost heterogeneous and consists of surgical and medical patients with different conditions which developed AKI. Given the complexity of the pathogenesis of AKI, it may be naïve to expect that therapeutic interventions would have significant success on outcome of these patients. Bagshaw et al. showed that almost $70 \%$ of physicians used loop diuretics at different stages/types of AKI which could be explained by the assumptive subsidence in AKI following diuresis establishment by diuretics administration. ${ }^{[19]}$ Our study revealed that no noticeable progress could be observed in AKI phase biomarkers which indicate recovery of renal function or decreasing in mortality following loop diuretic administration in the critically ill patients with AKI; these were in line with 


\begin{tabular}{|c|c|c|c|}
\hline & $\begin{array}{l}\text { AKI treated } \\
\text { with } \\
\text { furosemide } \\
(n=50)\end{array}$ & $\begin{array}{l}\text { AKI treated } \\
\text { without } \\
\text { furosemide } \\
(n=50)\end{array}$ & $P$ \\
\hline \multicolumn{4}{|c|}{ Creatinine (mg/dl) } \\
\hline $1^{\text {st }}$ day & $2.6 \pm 0.5$ & $2.8 \pm 0.3$ & 0.04 \\
\hline $3^{\text {rd day }}$ & $2.8 \pm 0.9$ & $3.2 \pm 1.2$ & 0.14 \\
\hline $7^{\text {th }}$ day & $2.6 \pm 1.1$ & $3.1 \pm 1.7$ & 0.055 \\
\hline \multicolumn{4}{|c|}{ BUN (mg/dl) } \\
\hline $1^{\text {st }}$ day & $46.3 \pm 9.9$ & $41.7 \pm 5.7$ & 0.01 \\
\hline $3^{\text {rd day }}$ & $57 \pm 20.6$ & $54.4 \pm 18.3$ & 0.49 \\
\hline $7^{\text {th }}$ day & $57.2 \pm 34.4$ & $58.8 \pm 32.5$ & 0.81 \\
\hline \multicolumn{4}{|c|}{ Urine NGAL (ng/ml) } \\
\hline $1^{\text {st }}$ day & $63.3 \pm 9.9$ & $60.7 \pm 9.6$ & 0.19 \\
\hline $3^{\text {rd day }}$ & $52.7 \pm 20.5$ & $53.6 \pm 17.2$ & 0.82 \\
\hline $7^{\text {th }}$ day & $41.1 \pm 27.5$ & $45.6 \pm 28.3$ & 0.42 \\
\hline \multicolumn{4}{|c|}{ Plasma NGAL (ng/ml) } \\
\hline $1^{\text {st }}$ day & $114.2 \pm 26.6$ & $131 \pm 22.9$ & 0.00 \\
\hline $3^{\text {rd day }}$ & $110.3 \pm 31.4$ & $124.4 \pm 35.9$ & 0.04 \\
\hline $7^{\text {th }}$ day & $93.1 \pm 50.1$ & $111 \pm 47.4$ & 0.07 \\
\hline
\end{tabular}

the results of the previous studies. ${ }^{[20,21]}$ Meta-analysis studies confirm that administration of loop diuretics in established AKI not only does not amend outcomes but also could be associated with increased risk of complications including hearing loss. ${ }^{[11,22]}$ Furthermore, an international cohort study suggested that diuretic administration resulted in increased mortality in established AKI; nevertheless, this was never approved by other similar studies. ${ }^{[5,10]}$ Diuretic administration did not lead to any significant complication or mortality in our study. In experimental models of AKI, loop diuretics decrease the severity of renal injury. ${ }^{[23]}$ Two main reasons were posed; (1) Diuresis, potentially washing out obstructing cellular debris and casts (2) Loop diuretics reduce the activity of $\mathrm{NaCl}$ transporters in the thick ascending limb of the loop of Henle and also maybe the terminal (S3) segment of the proximal tubule which lead to decreasing in energy consumption (by as much as $45 \%$ ). It may protect the tubular cells in the face of a decrease in energy delivery. ${ }^{[24,25]}$ Patients in diuretic group had lower mortality rate compared to control group which was not significant. This difference might be due to positive effects of furosemide on electrolyte imbalance especially hypokalemia, correction of acidosis and volume status of these patients. Furthermore, based on biomarker values in both groups of our study, the patients were given furosemide had not had worse profile of AKI phase biomarkers comparing with others. This may be explained by the fact that the incidence of established AKI in our patients was low and most of our patients were in RIFLE stages of 1 or 2. Despite this, primary and secondary outcomes of patients in two groups were the same which could have been due to the complexity and heterogeneity of AKI pathogenesis and the fact that variables mechanisms including

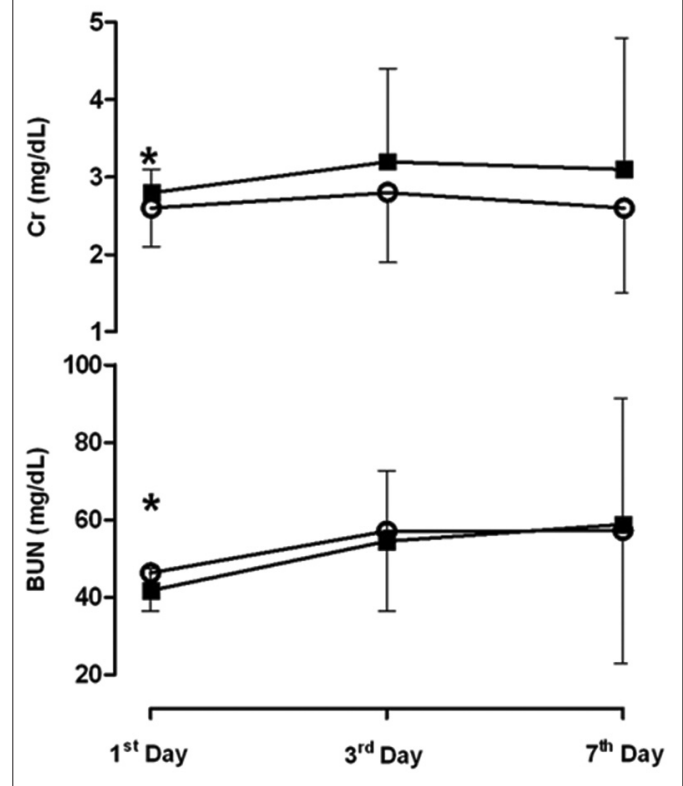

Figure 2: Changes in plasma concentration of $\mathrm{Cr}$ and BUN for Furosemide vs. control group by day. Open circles, Furosemide group; Solid Square, control group. This figure shows that only trend of $\mathrm{Cr}$ is significantly lower in Furosemide group comparing with control. ${ }^{\star} P<0.05$ for difference between $\mathrm{Cr}$ in Furosemide versus control group in first day after development of AKI

inflammation, coagulation, ischemia, toxins, and activation of $\mathrm{Na} / \mathrm{K} / \mathrm{Cl}$ cotransport in kidney are involved. Hence, to achieve a proper kidney function the mentioned criteria should be optimized.

Recently, NGAL has been suggested to be an appropriate correlation with kidney damage and therefore creating the hope for assistance in both early diagnosis and treatment. ${ }^{[26]}$ Bagshaw et al. reported that pNGAL had an area under the receiver operating curve (ROC) curve of 0.71 ( $95 \%$ confidence interval [CI], 0.55-0.88) for predicting AKI progression and of 0.78 (95\% CI, 0.61-0.95) for the need to renal replacement therapy. ${ }^{[27]}$ Cruz et al. reported an area under the ROC curve of 0.82 (95\% CI, 0.7-0.95) for predicting the use of renal replacement therapy ${ }^{[28]}$ Nickolas et al. reported that uNGAL remained low in patients admitted to the emergency department with prerenal azotemia versus AKI. ${ }^{[29]}$ Recent studies have demonstrated that following renal injury, uNGAL is upregulated early (within $2 \mathrm{~h}$ ) in a dose-dependent manner. ${ }^{[30]}$ Moreover, uNGAL and pNGAL increase in the AKI children following cardiac surgery. ${ }^{[31]}$ Therefore, NGAL might be of appropriate diagnostic value for the later occurrence of elevated $\mathrm{Cr}$ values in AKI. Similar accuracy of plasma and urinary NGAL was confirmed in a meta-analysis; whereas, uNGAL may be even superior in patients with chronic kidney diseases. ${ }^{[32]}$ Different studies showed that uNGAL is a better diagnostic marker compared to pNGAL for AKI. In the present study, there was not any difference between two groups regarding uNGAL which is an indicator for lack of efficacy of furosemide in AKI. ${ }^{[32]}$ 


\section{Limitation}

Our study was performed in only two hospitals with surgical ICUs; therefore, expansion of the results to all critical ill patients is not recommended. In addition, we did not follow-up patients for long term to evaluate the exact effect of our intervention on kidney function. Furthermore, KIM-1 and other markers of kidney injury were not assayed in our study due to funding limitations. The results of this study indicated that treatment with furosemide did not have a significant effect on markers of kidney function such as BUN/Cr and NGAL. Mortality of patients in furosemide group is lower than control group but did not have a significant difference.

Furosemide did not have significant positive or negative effect on kidney function and mortality of patients with AKI. This might be explained by complex pathology of AKI which includes many patholophysiologic insults. As these mechanisms are closely interlinked with each other, modulating one of these components simultaneously alter other components. Hence, furosemide as a single intervention is unlikely contributes to increased survival and management of these patients, should consist of global patient evaluation, early targeted treatment, continuous monitoring, and appropriate supportive care.

\section{Conclusions}

Furosemide has no harmful effects on kidney function in AKI patients, so we might use it for the management of patients with AKI. It is believed that pNGAL and uNGAL both are suitable markers for kidney function. However in this study NGAL was not found to reflect any positive or negative effects of Furosemide in patients with AKI.

\section{Acknowledgments}

Special thanks to Mr. Shahrokh Teshnedel, Mr. Qorbanali Tarinezhad and ICU staff of Shohada and Imam Reza hospitals for their cooperation during the study.

\section{Financial support and sponsorship}

Nil.

\section{Conflicts of interest}

There are no conflicts of interest.

\section{References}

1. Kellum JA, Bellomo R, Ronco C. The concept of acute kidney injury and the RIFLE criteria. Contrib Nephrol 2007;156:10-6.

2. Mehta RL, Cantarovich F, Shaw A, Hoste E, Murray P. Pharmacologic approaches for volume excess in acute kidney injury (AKI). Int J Artif Organs 2008;31:127-44.

3. Mehta RL. Fluid balance and acute kidney injury: The missing link for predicting adverse outcomes? Nat Clin Pract Nephrol 2009;5:10-1.

4. Bagshaw SM, Brophy PD, Cruz D, Ronco C. Fluid balance as a biomarker: Impact of fluid overload on outcome in critically ill patients with acute kidney injury. Crit Care 2008;12:169.

5. Uchino S, Doig GS, Bellomo R, Morimatsu H, Morgera S, Schetz M, et al. Diuretics and mortality in acute renal failure. Crit Care Med 2004;32:1669-77.

6. Lassnigg A, Donner E, Grubhofer G, Presterl E, Druml W, Hiesmayr M.
Lack of renoprotective effects of dopamine and furosemide during cardiac surgery. J Am Soc Nephrol 2000;11:97-104.

7. Cantarovich F, Rangoonwala B, Lorenz H, Verho M, Esnault VL; High-Dose Flurosemide in Acute Renal Failure Study Group. High-dose furosemide for established ARF: A prospective, randomized, double-blind, placebo-controlled, multicenter trial. Am J Kidney Dis 2004;44:402-9.

8. Mehta RL, Pascual MT, Soroko S, Chertow GM; PICARD Study Group. Diuretics, mortality, and nonrecovery of renal function in acute renal failure. JAMA 2002;288:2547-53.

9. Swärd K, Valsson F, Sellgren J, Ricksten SE. Differential effects of human atrial natriuretic peptide and furosemide on glomerular filtration rate and renal oxygen consumption in humans. Intensive Care Med 2005;31:79-85.

10. Ho KM, Sheridan DJ. Meta-analysis of frusemide to prevent or treat acute renal failure. BMJ 2006;333:420.

11. Rastogi S, Bayliss JM, Nascimento L, Arruda JA. Hyperkalemic renal tubular acidosis: Effect of furosemide in humans and in rats. Kidney Int 1985;28:801-7.

12. Lee CT, Chen HC, Lai LW, Yong KC, Lien YH. Effects of furosemide on renal calcium handling. Am J Physiol Renal Physiol 2007;293:F1231-7.

13. Zhang Z, Lu B, Sheng X, Jin N. Cystatin C in prediction of acute kidney injury: A systemic review and meta-analysis. Am J Kidney Dis 2011;58:356-65.

14. Damman K, Ng Kam Chuen MJ, MacFadyen RJ, Lip GY, Gaze D, Collinson PO, et al. Volume status and diuretic therapy in systolic heart failure and the detection of early abnormalities in renal and tubular function. J Am Coll Cardiol 2011;57:2233-41.

15. Makris K, Markou N, Evodia E, Dimopoulou E, Drakopoulos I, Ntetsika $\mathrm{K}$, et al. Urinary neutrophil gelatinase-associated lipocalin (NGAL) as an early marker of acute kidney injury in critically ill multiple trauma patients. Clin Chem Lab Med 2009;47:79-82.

16. Zappitelli M, Washburn KK, Arikan AA, Loftis L, Ma Q, Devarajan P, et al. Urine neutrophil gelatinase-associated lipocalin is an early marker of acute kidney injury in critically ill children: A prospective cohort study. Crit Care 2007;11:R84.

17. Wheeler DS, Devarajan P, Ma Q, Harmon K, Monaco M, Cvijanovich N, et al. Serum neutrophil gelatinase-associated lipocalin (NGAL) as a marker of acute kidney injury in critically ill children with septic shock. Crit Care Med 2008;36:1297-303.

18. Bellomo R, Ronco C, Kellum JA, Mehta RL, Palevsky P; Acute Dialysis Quality Initiative Workgroup. Acute renal failure-definition, outcome measures, animal models, fluid therapy and information technology needs: The Second International Consensus Conference of the Acute Dialysis Quality Initiative (ADQI) Group. Crit Care 2004;8:R204-12.

19. Bagshaw SM, Delaney A, Jones D, Ronco C, Bellomo R. Diuretics in the management of acute kidney injury: A multinational survey. Contrib Nephrol 2007;156:236-49.

20. Cotter G, Weissgarten J, Metzkor E, Moshkovitz Y, Litinski I, Tavori U, et al. Increased toxicity of high-dose furosemide versus low-dose dopamine in the treatment of refractory congestive heart failure. Clin Pharmacol Ther 1997;62:187-93.

21. van der Voort PH, Boerma EC, Koopmans M, Zandberg M, de Ruiter J, Gerritsen RT, et al. Furosemide does not improve renal recovery after hemofiltration for acute renal failure in critically ill patients: A double blind randomized controlled trial. Crit Care Med 2009;37:533-8.

22. Bagshaw SM, Delaney A, Haase M, Ghali WA, Bellomo R. Loop diuretics in the management of acute renal failure: A systematic review and meta-analysis. Crit Care Resusc 2007;9:60-8.

23. Hanley MJ, Davidson K. Prior mannitol and furosemide infusion in a model of ischemic acute renal failure. Am J Physiol 1981;241:F556-64.

24. Escalante B, Erlij D, Falck JR, McGiff JC. Effect of cytochrome P450 arachidonate metabolites on ion transport in rabbit kidney loop of Henle. Science 1991;251:799-802.

25. Heyman SN, Rosen S, Epstein FH, Spokes K, Brezis ML. Loop diuretics reduce hypoxic damage to proximal tubules of the isolated perfused rat kidney. Kidney Int 1994;45:981-5.

26. Liangos O, Perianayagam MC, Vaidya VS, Han WK, Wald R, Tighiouart H, et al. Urinary N-acetyl-beta-(D)-glucosaminidase activity and kidney injury molecule-1 level are associated with adverse outcomes 
in acute renal failure. J Am Soc Nephrol 2007;18:904-12.

27. Bagshaw SM, Langenberg C, Wan L, May CN, Bellomo R. A systematic review of urinary findings in experimental septic acute renal failure. Crit Care Med 2007;35:1592-8.

28. Cruz DN, Soni S, Ronco C. NGAL and cardiac surgery-associated acute kidney injury. Am J Kidney Dis 2009;53:565-6.

29. Nickolas TL, O'Rourke MJ, Yang J, Sise ME, Canetta PA, Barasch N, et al. Sensitivity and specificity of a single emergency department measurement of urinary neutrophil gelatinase-associated lipocalin for diagnosing acute kidney injury. Ann Intern Med 2008;148:810-9.

30. Mishra J, Ma Q, Prada A, Mitsnefes M, Zahedi K, Yang J, et al.
Identification of neutrophil gelatinase-associated lipocalin as a novel early urinary biomarker for ischemic renal injury. J Am Soc Nephrol 2003;14:2534-43

31. Mishra J, Dent C, Tarabishi R, Mitsnefes MM, Ma Q, Kelly C, et al. Neutrophil gelatinase-associated lipocalin (NGAL) as a biomarker for acute renal injury after cardiac surgery. Lancet 2005;365:1231-8.

32. Haase M, Bellomo R, Devarajan P, Schlattmann P, Haase-Fielitz A; NGAL Meta-analysis Investigator Group. Accuracy of neutrophil gelatinase-associated lipocalin (NGAL) in diagnosis and prognosis in acute kidney injury: A systematic review and meta-analysis. Am J Kidney Dis 2009;54:1012-24. 